\title{
A CASE OF SCHWANNOMA OF THE NASAL SEPTUM
}

Shankar Tati ${ }^{1}$, Shobhan Babu A2 ${ }^{2}$ Durga Prasad K. V. N3 , Anjani Kumari K', Yugandhar E ${ }^{5}$

\section{HOW TO CITE THIS ARTICLE:}

Shankar Tati, Shobhan Babu A, Durga Prasad K. V. N, Anjani Kumari K, Yugandhar E. "A Case of Schwannoma of the Nasal Septum". Journal of Evolution of Medical and Dental Sciences 2014; Vol. 3, Issue 63, November 20; Page: 13945-13949, DOI: $10.14260 /$ jemds/2014/3865

ABSTRACT: Schwannomas are benign tumor of nerve sheath and quite uncommon in the nasal septum. This tumor most frequently originating from the acoustic nerve in the head and neck region, $45 \%$ of all schwannomas occur in body and $25 \%$ as extracranial schwannomas. Tumor arising from nasal septum are extremely rare with only 16 cases having been reported in the literature. We are here presenting a rare of case of nasal septal schwannoma in 40 years old male patient, removed by endoscopic approach no recurrence found, HPE report confirms schwannoma.

KEYWORDS: Schwannoma, Nerve Sheath Tumor, Nasal Septum, Anterior Rhinoscopy, Lateral Rhinotomy.

INTRODUCTION: A case of Neurilemmoma of Nasal Septum was first described by Bogdasanian and Stout,(1) schwannoma was benign encapsulated nerve sheath neoplasm composed of Schwann cells first described by verocay in 1908, stout (1935) coined the term neurilemmoma believing that this tumor arises from cells of sheath of Schwann which may also develop in any part of the body. Tumor arising from the nasal septum are extremely rare, incidence is 1 in 3000, schwannomas treatment of choice is surgical removal by lateral rhinotomy or endoscopic guided depending up on the size and extent of the Tumor.

CASE REPORT: A 40 year old male patient presented with progressive right sided nasal obstruction, mass in the (R) nostril, and external deformity of nose for 5 months, he had headache associated with loss of sensation (R) side of cheek and forehead. Anterior rhinoscopy revealed a large polypoidal mass completely filling the (R) nasal cavity, firm in consistency and bleeding on touch origin of mass could not be determined due to huge mass. Patient was subjected for necessary investigations along with CT scan PNS revealed. (Fig No.1 \& 2). A homogenous mass measuring 30x10x15mm lying with in the mid portion of nasal cavity, arising from right nasal septum. The lesion well defined with smooth margins and without calcification.

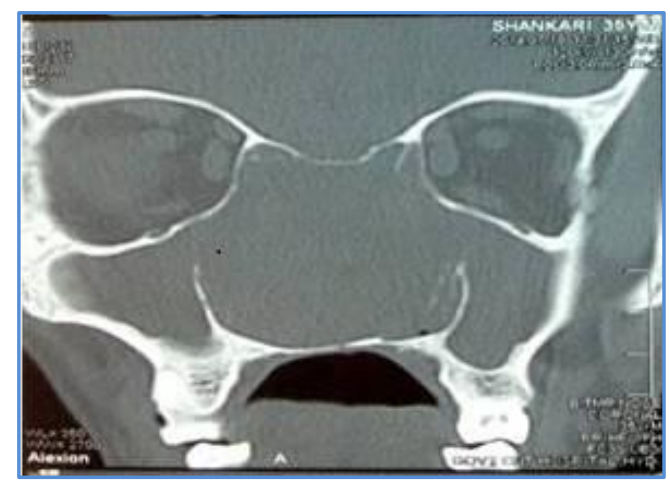

Fig. 1: Pre OP CT Scan Photo

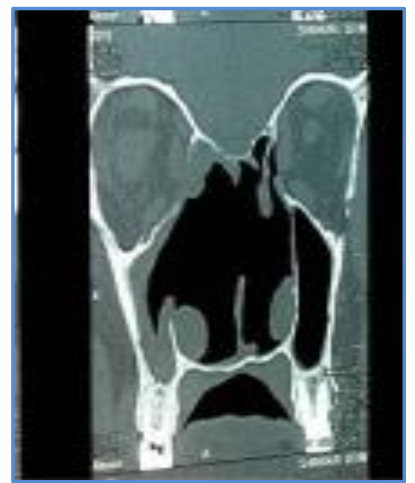

Fig. 2: Post OP CT Scan Photo 


\section{CASE REPORT}

A homogenous mass measuring about $30 \times 16 \times 15 \mathrm{~mm}$ lying with in the mid portion of nasal cavity, arising from (R) nasal septum, the lesion well defined with smooth margins and without calcification patient taken up for surgery (Endoscopic Excision) under general anesthesia, first we did finger dissection than under endoscopic guidance tumor was removed which was attached to the posterior end of nasal septum in view of total removal of tumor, sent for HPE, nasal packing was done with BIPP post-operative recovery was uneventful, pack was removal after 24 hours, discharged after 5days after doing DNE and nasal douching was done. Patient is under follow up by time of writing this article. No recurrence was found. (Figure No.3)

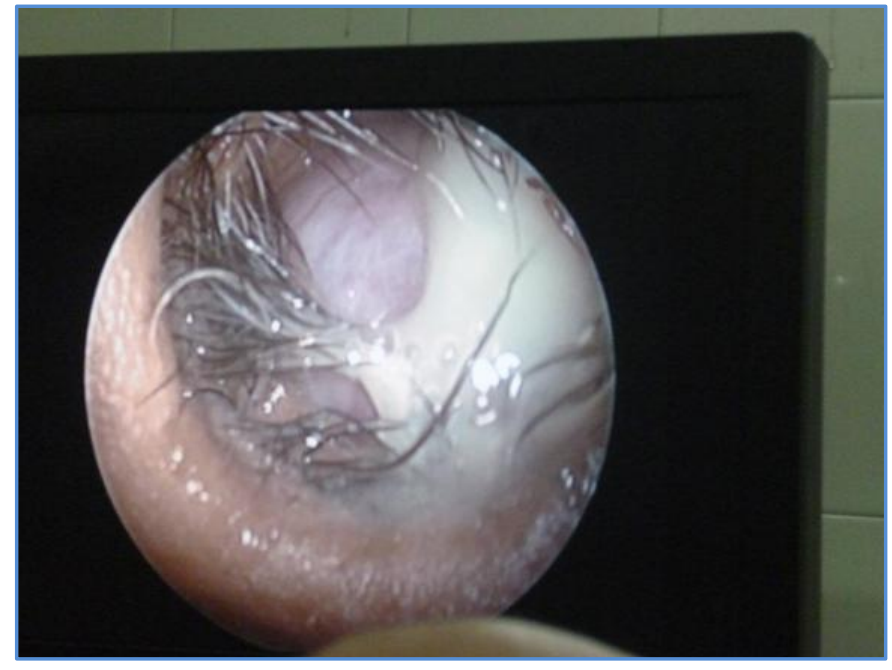

Fig. 3: Preoperative Photo

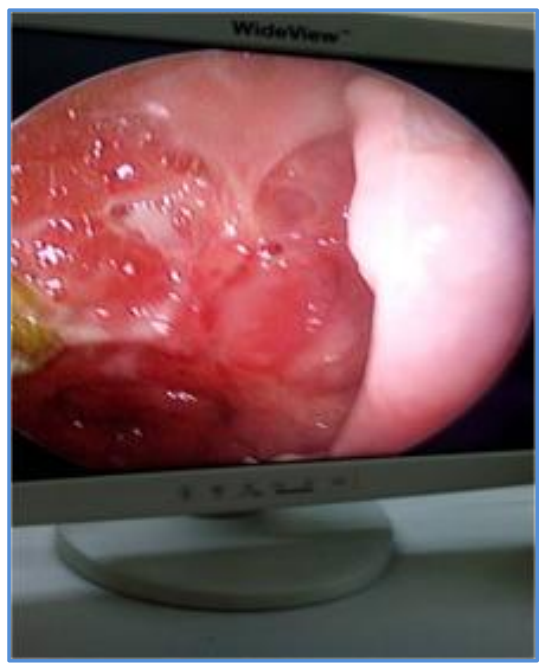

Fig. 3: Postoperative Photo

The HPE Report: Neurogenic tumor, schwannoma with nuclear a typia, Ki67 proliferative index was advised, Ki67 was low indicate a benign Tumor, under high power - Verocay bodies seen. (Fig No.4 \& 5).

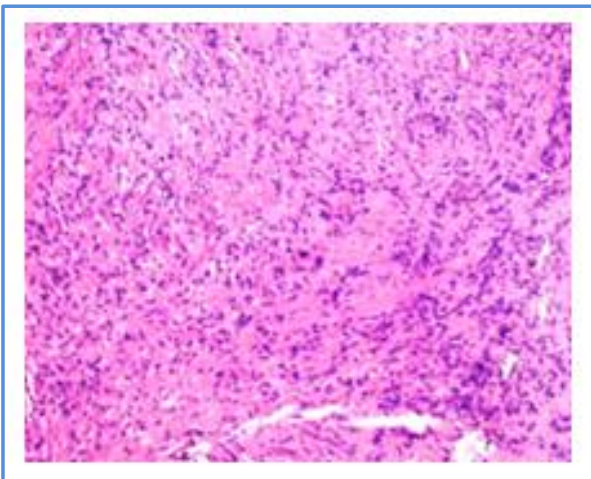

Fig. 4: LOW POWER

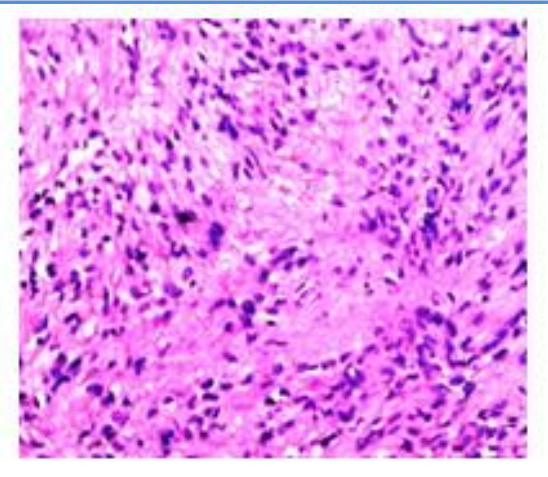

Fig. 5: HIGH POWER

DISCUSSION: The neural origin of the Schwannomas is considered to be from peripheral motor, sensory, sympathetic and cranial nerve sheath ${ }^{(2,3)}$ nasal schwannoma are presumed to be arising from the sheath of the ophthalmic and maxillary branches of the trigeminal nerve and antomoci ganglia.(4) The optic and olfactory cranial nerves are not potential sites of the origin, since they lack 


\section{CASE REPORT}

sheaths that contain Schwann cells and since nasal schwannomas are sometimes removed without loss of original nerve functions, it is usually difficult to determine the neural origin. Schwannomas of the sinonasal tract are very infrequent, representing less than $4 \%$ of the schwannomas of the head and neck.(5) In this location they have been reported in patients between the age of 6years and 78 years. There is no sex or racial predilection.(6)

The ethmoidal sinus is most commonly involved, followed by the maxillary sinus, nasal fossa and sphenoid sinus.(7) Localization to the nasal septum is exceedingly rare. Septal schwannomas arise from the autonomic or sensory nerves within the nasal septum. There is no apparent site predilection on the septum. Symptoms are non-specific and are the result of the mass effect or tumor necrosis. Patients may present with nasal obstruction, rhinorrhea, or recurrent epistaxis, Nasal obstruction is the most common clinical symptom followed by epistaxis. $(8,9)$

Facial swelling and pain are associated with paranasal sinus involvement. These lesions rarely undergo malignant transformation. Computerized tomography (CT) delineates an image of the soft tissue tumor and simultaneously outlines the skeletal margins well enough to rule out invasion and demonstrated central lucency and peripheral enhancement after contrast administration in case of schwannomas because peripheral neovascular areas of the tumor are enchanced in contrast with nonenhancing necrotic or cystic regions. Although magnetic resonance imaging (MRI) is superior in defining soft tissue tumors, CT offers better resolution of bony invasion. However, as benign schwannoma can erode bone by pressure, bony erosion is not a criterion for malignancy.(10)

Microscopically, schwanomas can exhibit two architectural patterns. Antoni type A and Antoni type B, in different proportions.

Antoni type A area is composed of an organized compact cellular stroma with elongated spindle cells. Parallel rows of palisading nuclei can be seen in this highly differentiated tissue. Antoni type B area is composed of disorganized loose myxoid stroma with few spindle cells. Additionally, schwannomas usually show intense immunostaining for S100 protein (particularly Antoni A areas).(11) This may help to distinguish peripheral nerve sheath neoplasm from other tumors. The nasal septum appears to be the most common location for this lesion. The main differential diagnoses of nasal masses with similar MRI/CT findings as schwannoma include nasal polyp, malignant peripheral nerve sheath tumors (MPNST), myxoma \& fibromyxoma, Lobular Capillary hemangioma (LCH) and sarcoma. Nasal polyps represent hyperplasia of the mucosa in response to chronic inflammation, usually from chronic sinusitis.

Nasal polyps usually have high signal intensity on T2-weighted images, which helps to distinguish them from tumors; Myxoma \& fibromyxoma are benign neoplasm of uncertain histogenesis with characteristic histologic appearance. When relatively a greater amount of stomal collagen if present, the term fibromyxoma (or myxofibroma) is used. Histologically these tumor show scanty, loose cellular proliferation containing spindle-shaped or stellate-appearing cells embedded in abundant mucinous stroma. This tumor can manifest as a well-marginated mass but may also show local infiltration and local invasion.(12)

MPNS tumors show features of malignancy, high mitotic count and with or without heterologous elements which will be lacking in schwannomas. Other sarcomas similarly show higher pleomorphism with absence of neural differentiation. LCH is most often found in the anterior portion of the nasal septum.(13) Histologically LCH is characterized by submucous vascular proliferation arranged in lobules of clusters composed of central capillaries and smaller ramifying tributaries. 
The only treatment for schwannoma is wide local excision through an approach allowing adequate exposure as schwannoma are generally radioresistant. But in treating benign schwannoma, functional and cosmetic consideration should be taken into account. Recently the technique of endoscopic nasal surgery has rapidly developed and transnasal endoscopic excision of benign tumors of the nose paranasal sinuses and nasal septum has been successful (14). The tumor mass in our case was successfully excised by transnasal endoscopic approach. A single schwannoma does not recur when completely excised.

CONCLUSION: We report a 40 years old male patient with nasal septal schwannoma which was successfully treated by transnasal endoscopic excision, the schwannomas of the nasal septum is extremely rare; the possibility of their existence should be realized and included in the differential diagnosis of any nasal mass, malignant transformation is very in this cases.

\section{REFERENCES:}

1. Bogdasarian RM, Stout AP. Neurilemmoma of the nasal septum. Arch Otolaryngol. 1943; 38: 6264.

2. Pasic TR, Makielski K. Nasal schwannoma. Otolaryngol, Head Neck Surg. 1990: 103: 943-946.

3. Thomas JN. Massive schwannoma arising from the nasal septum. J Laryngol Otol. 1977; 91: 6368.

4. Batsakis J. Tumours of the Head and Neck Clinical and Pathological Considerations. $2^{\text {nd }}$ ed. Baltimore. MD: Williams and Wilkins; 1979, 313-333.

5. Berlucchi M, Piazza C, Blanzuoli L et al. Schwannoma of the nasal septum: a case report with review of the literature. Eur Arch Otorhinolaryngol. 2000; 257: 402-405.

6. Ross C, Wright E, Moseley J et al. Massive schwannoma of the nose and paranasal sinuses. South Med J. 1988; 81: 1588-1591.

7. Calceterra TC, Rich R, Ward PW. Neurilemmoma of the sphenoid sinus. Arch Otolaryngol. 1974; 100: 383-385.

8. Oi H, Watanabe Y, Shojaku H et al. Nasal septal neurinoma. Acta Otolaryngol. (Stockh). 1993 (Suppl.504); 151-154.

9. Enion DS, Enkins A, Miles JB et al. Intracrnial extension of a naso-ethmoid schwannoma. J Laryngol Otol. 1991; 105: 578-581.

10. Younis RT, Gross CW, Lazar RH. Schwannomas of the paranasal sinuses: case report and clinicopathologic analysis. Arch Otolaryngol Head Neck Surg, 1991: 117-677-680.

11. Donnelly MJ, Hussain M, Blayney AW. Benign nasal schwannoma. J Laryngol Otol. 1992; 106: 1011-1015.

12. Fu YS, Perzin KH. Nonepithelial tumors of nasal cavity, paranasal sinuses, and nasopharynx: a clinicopathological study- General features and vascular tumor. Cancer. 1974; 33: 1275-1288.

13. Sheppard IM, Michaelson SA. Hemangioma of the nasal septum and paranasal sinuses. Henry Ford Hosp Med J.1990; 38: 25-27.

14. Kang ST, Kim JH, Cho CS et al. A case of neurilemmoma arising from nasal septum. Korean J Otolaryngol. 1995; 38: 126-129. 


\section{CASE REPORT}

\section{AUTHORS:}

1. Shankar Tati

2. Shobhan Babu A.

3. Durga Prasad K. V. N.

4. Anjani Kumari K.

5. Yugandhar E.

\section{PARTICULARS OF CONTRIBUTORS:}

1. Professor, Department of ENT, Osmania Medical College, Hyderabad.

2. Associate Professor, Department of ENT, Osmania Medical College, Hyderabad.

3. Assistant Professor, Department of ENT, Osmania Medical College, Hyderabad.

4. Assistant Professor, Department of ENT, Osmania Medical College, Hyderabad.
5. Resident, Department of ENT, Osmania Medical College, Hyderabad.

\section{NAME ADDRESS EMAIL ID OF THE} CORRESPONDING AUTHOR:

Dr. Shankar Tati,

\# 12-5-149/6/A,

Sajja Amubience, Flat No. 201,

Vijayapuri, Tarnaka,

Hyderabad-500017,

Telangana, India.

Email: drshankar_ms@yahoomail.com

Date of Submission: 03/11/2014.

Date of Peer Review: 04/11/2014.

Date of Acceptance: 15/11/2014.

Date of Publishing: 20/11/2014. 